\title{
O ACONSELHAMENTO PSICOLÓGICO E AS POSSIBILIDADES DE UMA (NOVA) CLÍNICA PSICOLÓGICA
}

\author{
FERNANDO DE BARROS \\ AdRIANO HOLANDA
}

\begin{abstract}
Resumo: A partir da reflexão sobre as bases epistemológicas da Psicologia, este trabalho tem como objetivo verificar questões fundamentais à clínica psicológica. Algumas dificuldades principais em relação ao objeto científico da ciência psicológica são abordadas, sendo propostos fundamentos fenomenológicos que poderiam ser úteis na tentativa de apropriação e compreensão deste objeto psicológico. Pode ser possível fundamentar uma prática clínica constituída por uma compreensão mais profunda dos fenômenos humanos que são experienciados com sofrimento pelo sujeito em foco, seguido de um subseqüente e inevitável cuidado. Tais elementos parecem existir somente em um lugar comum produzido no encontro entre duas subjetividades distintas. Dessa forma, a clínica psicológica pode ocorrer em uma variedade de contextos, além daqueles nos quais ela já acontece. O aconselhamento psicológico, entendido aqui como uma possibilidade de ocorrência desse encontro clínico fundamental, mesmo que em um gradiente temporal reduzido, pode então ter um lugar no espectro da clínica psicológica clássica.
\end{abstract}

Palavras-chave: Aconselhamento Psicológico; Fenomenologia; Psicologia Clínica; Epistemologia.

\section{Introdução}

A atuação psicológica parece ter sido sempre pensada em espaços e tempos bastante particulares. Desde o estabelecimento de um ponto de vista organicista ${ }^{1}$ sobre as enfermidades mentais as questões referentes ao abstrato humano ainda têm sido tratadas, de modo geral, sob uma perspectiva asilar. Asilar no sentido real, com o desenvolvimento dos primeiros manicômios e, também, no sentido clínico, a respeito dos fenômenos tipicamente humanos que se mostravam de um modo suficientemente distinto dos demais. E que suficiência seria essa?

Historicamente ocorrendo em um espaço bastante específico, pelo menos a partir da Idade Contemporânea, o lidar com os fenômenos humanos - estes sendo até hoje suficientemente incompreendidos -, parece demandar, justamente por essa suficiência, um novo espaço. Se essa própria história presenciou a extinção de várias instituições manicomiais - na qual a Reforma Psiquiátrica teve um papel bastante expressivo -, pode-se ainda notar, entretanto, que o espaço reservado ao abstrato humano ainda é restrito, mesmo quando o espaço em questão é o espaço terapêutico.

Refletir em algum grau essa suficiência e também essa possibilidade de um novo espaço, no sentido de compreender a qualidade do pensamento sobre os

\footnotetext{
${ }^{1}$ A clássica visão organicista pressupõe um substrato orgânico às afecções mentais; considera-se que a doença é sinônimo de uma alteração da estrutura física de um indivíduo devido a uma desordem corporal; logo, legitima-se a prática da anatomia. Esse ponto de vista encontra-se representado em diversos contextos da Psicologia (Szasz, 1979; Foucault, 1987).
} 
fenômenos psicológicos e de sugerir a ampliação dos contextos terapêuticos nos quais essa prática seria possível pode ser útil para o início da reflexão das possibilidades de um lugar para uma nova clínica psicológica.

\section{As (in)sufi-ciências}

O significado semântico da palavra "suficiente” é, de fato, suficiente, para o início dessa nossa reflexão: "1. Que satisfaz; bastante. 2. Que está entre o bom e o sofrível. (...)” (dicionário Aurélio, grifo do autor). Porém não é o bastante, sendo isso semanticamente contraditório ou não.

Antes de se falar desse "lugar" entre o bom e o sofrível, talvez seja interessante um breve resgate histórico da ciência psicológica. Na verdade, não caberia aqui um simples "breve" resgate. Pela própria problemática da constituição da Psicologia como uma ciência independente, essa brevidade já seria demasiado longa, e aquele "simples" demasiado complexo.

Ocorre que o saber psicológico de alguma forma, sempre possuiu vínculos inevitáveis com outras ciências. Isso parece ter ocorrido principalmente pela dificuldade de se especificar o objeto da ciência psicológica, processo epistemológico indispensável para qualquer ciência constituir-se como tal. Outras ciências humanas, em princípio, não demonstraram tão explicitamente essa dificuldade. De fato, o objeto da Psicologia ainda hoje carece de um consenso absoluto, apesar do avanço da constituição científica da Psicologia como uma ciência independente ser inegável; talvez já suficiente, inclusive, para justificar sua prática.

Duas importantes condições poderiam traduzir, respectivamente, as idéias de delimitação do objeto psicológico e do conhecer deste objeto, já sob um olhar clínico - inerentes à Psicologia científica: 1) a experiência de uma subjetividade privatizada; e 2) a experiência da crise dessa subjetividade privatizada (Figueiredo \& Santi, 2003). A partir dessa contribuição, isto é, concebendo a Psicologia como a ciência da subjetividade privatizada, alguns aspectos referentes à qualidade do alcance e da compreensão de tal subjetividade podem ser tratados.

O problema do objeto da ciência psicológica pode estar essencialmente associado com a dificuldade na delimitação e captação deste objeto enquanto fenômeno ${ }^{2}$. Enquanto que nas ciências exatas a experiência empírica é capaz de produzir essa compreensão do objeto estudado, seja por meio indutivo ou dedutivo, nas ciências humanas esse método não se mostrou tão eficaz. Na verdade, a própria ciência exata não conta com a certeza experimental, isto é, dito daquela forma, fica a impressão de que o problema do conhecer está resolvido nas ciências exatas, e isso parece não ser verdade.

\footnotetext{
${ }^{2}$ A idéia de captação enquanto fenômeno do objeto psicológico será aprofundada adiante. Convém já nesse momento, assinalar que a intenção aqui é enfatizar a necessidade de uma compreensão deste objeto, e não apenas seu conhecimento a partir de processos explicativos, empreendimento a ser tentado segundo uma base teórica e de um método específico que estejam cientes dessa questão.
} 
Essa questão do objeto científico parece ser muito mais complexa especialmente no caso da Psicologia. Conforme já dito, o problema advém não só da dificuldade de se delimitar o objeto de investida psicológica, como também da possível impossibilidade de se chegar a uma compreensão absoluta deste objeto enquanto fenômeno. Assim, a partir de tais dificuldades, fica mais claro entender, na perspectiva histórica da clínica psicológica - incluso aqui a psiquiatria clássica - por que motivos os primeiros manicômios continham todo tipo de pessoas (Foucault, 1978, 1984), e não somente aqueles que pareciam ter (ou não ter) alguma coisa - a mais ou a menos - em termos mentais (ou mesmo não-mentais).

Se hoje, com toda investigação científica, permanece o problema do conhecer em Psicologia - devido à problemática do objeto de estudo -, o que se podia esperar há três ou quase quatro séculos atrás?

O abstrato humano, a subjetividade privatizada, talvez ainda permaneça insuficientemente compreendida também na clínica. A Psicologia, não conseguindo se apropriar desse objeto enquanto fenômeno, também não poderia questionar a respeito das nuanças deste objeto, fato este que poderia colocar a clínica psicológica em cheque.

Binswanger, citado por Bucher (1989), reconhecendo a insatisfação dos arcabouços científicos herdados da psiquiatria - construída sob as bases das ciências naturalistas e do pensamento positivista - expressa que "a psiquiatria e psicologia tratam 'do homem', não em primeiro lugar do homem mentalmente enfermo, mas do homem em si (...)” (p. 29). De fato, as ciências do homem teriam como objeto o homem e não apenas o homem enfermo, ou a subjetividade humana, e não apenas a subjetividade humana em crise. Esta mesma posição encontra-se marcada no pensamento de Karl Jaspers (1987) quando, no seu Psicopatologia Geral, afirma ser o "indivíduo humano todo" do qual se ocupa o profissional.

Aqui caberia uma ressalva: dado que esta apropriação caminha na direção de um dinamismo intrínseco, ou seja, não cabendo uma apreciação atomística deste sujeito humano, melhor seria falarmos de subjetivação no lugar de subjetividade.

Contudo, ambos os saberes - Psiquiatria e Psicologia - parecem de fato justificarem-se somente quando em suas respectivas práticas, algo que, historicamente, foi marcado necessariamente pelo tratamento do sujeito enfermo e não simplesmente do sujeito.

Sendo exatamente a possibilidade desse questionamento do abstrato humano que torna capaz o juízo, isto é, a categorização ou a classificação deste abstrato - e, logo, a possibilidade de atuação sobre este a partir daquele juízo constatado -, poderse-ia admitir uma indagação a respeito da justificativa da clínica psicológica sustentada dessa forma. Aqui, interessa enfim apontar que, historicamente, a clínica psicológica parece ter se fundamentado em três importantes insuficiências: a) em primeiro lugar, a insuficiência da delimitação de seu objeto de estudo, cuja impalpabilidade faz com que a idéia de sujeito estudada possa vir a ser confundida com outras ciências (como a antropologia, por exemplo); b) segundo, e conseqüente à primeira insuficiência, a utilização preliminar de um método, que não se mostrou satisfatório para acessar o 
mundo privado dessa subjetivação, e; c) terceiro, a própria constituição dessa idéia de subjetividade privatizada, que em diversos momentos - em especial, no tocante à clínica - mostra-se alheia à sua contextualização histórica, ou seja, apresenta-se indevidamente deslocada de um "tempo" (de uma história) e de um "espaço" (locus) que é invariavelmente social e cultural.

Distinguindo-se virtualmente os campos da Psicologia enquanto ciência psicológica e enquanto atividade clínica constata-se que, tanto com relação à primeira insuficiência (objeto) quanto à segunda (método, apropriação), é possível que essas duas dificuldades apresentem-se ainda mais críticas no segundo campo citado, isto é, na clínica psicológica. Assim, repousa aqui a questão: como a prática psicológica, que propõe uma terapêutica para a crise dessa subjetividade privatizada poderia então ser possível na ausência de uma compreensão suficiente deste objeto psicológico, resultado tanto da dificuldade de delimitação quanto de alcance desse objeto a ser investido terapeuticamente? E quanto à terceira réplica, parece-nos que a mesma encontra-se intimamente relacionada à primeira.

Sob a problemática apresentada, poder-se-ia considerar, entretanto, que as dificuldades até aqui apontadas concentram-se mais na dificuldade de apropriação desse objeto científico e já não tanto a respeito da identificação deste. De tal modo que, satisfazendo-nos com a idéia de "subjetividade privatizada", resta a questão metodológica a respeito daquela compreensão suficiente dessa subjetividade:

A procura de um método torna-se um dos problemas mais importantes de todo empreendimento para a compreensão das formas caracteristicamente humanas de atividade psicológica. Nesse caso, o método é, ao mesmo tempo, pré-requisito e produto, o instrumento e o resultado do estudo. (Vygotsky, 2002, p.6)

Na história da Psicologia, a intenção de dar autenticidade ao pensamento psicológico refletiu-se na busca, entre as ciências da natureza, de métodos que justificassem tal saber; em princípio, esses métodos foram buscados na Biologia, especialmente na Fisiologia (Faria \& Brandão, 2004) e nas ciências físicas. Existiu ainda uma tentativa de encontrar um método satisfatório à Psicologia a partir da influência de outras ciências humanas, como a Sociologia. Ocorre que a questão do método em Psicologia também não parece estar definitivamente encerrada.

Neste momento, como uma tentativa de pensar um método mais efetivo à compreensão do abstrato humano, uma perspectiva fenomenológica poderia ter um lugar nessa questão.

A Fenomenologia, mais do que propriamente uma escola filosófica bem delimitada sistematicamente, pode ser entendida como um movimento de idéias (Holanda, 2002) que, em princípio, buscava uma nova compreensão dos fenômenos naturais com o intuito de superar a crise das ciências observada na época de sua 
emergência, entre o final do século XIX e o início do século XX (Husserl, 1965, 1980, 1985, 1989, 1992; Kolakowski, 1983).

No decorrer de sua história, a perspectiva fenomenológica claramente assumiu a sua preocupação de intentar a compreensão dos fenômenos através de um método bastante particular, sustentado por uma série de fundamentos também particulares, que culminaram em uma construção teórico-filosófica considerável. Todo o saber fenomenológico construído ao largo de cinco décadas foi esboçado por Edmund Husserl - na esteira das reflexões de Franz Brentano e Wilhelm Dilthey - e desenvolvido por este e por muitos outros autores como Maurice MerleauPonty, Jean-Paul Sartre, Karl Jaspers, Max Scheler e Martin Heidegger.

Parece ter existido, em todos os pensadores desse movimento, a preocupação de se chegar a uma compreensão essencial de um determinado fenômeno observado. Na verdade, essa idéia não se restringe ao pensamento fenomenológico; trata-se de uma preocupação das filosofias como um todo.

A atitude filosófica de buscar a essência dos entes, de intentar encontrar seus conceitos fundamentais, através do questionamento, da indagação daquilo que achamos que conhecemos (Buzzi, 1989), esteve sempre presente, desde os primeiros tempos, na história do percurso filosófico. Poder-se-ia dizer que essa atitude confunde-se com a própria definição de filosofia, mesmo que esta não possa repousar sob uma definição consensual. Na clássica questão filosófica do problema do ser, por exemplo, o pensamento de Parmênides de Eléia (aproximadamente século $\mathrm{V}$ a.C.) refletiu bem a questão da investigação do ser em termos fundamentais: o conhecimento desse ser, do que é, seria proveniente do estudo desse próprio ser, e não daquilo que não é (Bornheim, 1993).

Sob esta perspectiva, há de se considerar, a princípio, que o objeto do qual é tentada a aproximação parece existir, de fato, somente em um fundo dialético composto pelo próprio objeto enquanto fenômeno, e pela consciência daquele que se aproxima deste objeto. A idéia de intencionalidade, pressupondo uma postura ativa da consciência a fim de alcançar este fenômeno em sua essência, vai ao encontro desta consideração (Lyotard, 1954). Assim, enquanto que em outras ciências, especialmente nas exatas, o objeto de estudo parece vir de encontro ao observador (que apenas teria o difícil papel de estabelecer as condições básicas para tal movimento), na ciência dos fenômenos humanos tal apropriação se daria de um modo muito mais complexo. Não é o objeto que caminha ao encontro do observador, tampouco é este último que avança ao objeto. A consciência daquele que intenciona a essência do fenômeno almejado e o mostrar-se deste àquela consciência intencional constituiriam, portanto, um movimento dialético, definido enquanto resultado de interações que se produziriam a meio caminho entre sujeito e objeto (Piaget, 2002).

Ressalvadas as diferenças conceituais entre a idéia de ser de Parmênides e a idéia de fenômeno aqui considerada, o pressuposto do conhecer a essência dos fatos observados por meio do próprio objeto é, na verdade, levado a cabo somente quando se faz presente a síntese ser e pensar, ou fenômeno e consciência. 
Adiante, será considerada, de um modo mais completo, a questão sobre como conceber o abstrato humano que se apresentaria (ou seria entendido) como diferente. Desde esse momento, no entanto, é possível traçar alguns pontos referentes à tentativa de aproximação fenomenológica desse abstrato humano que, nesse sentido, em princípio, simplesmente não importa ser considerado comum ou diferente, mesmo porque, tal predicado estaria localizado somente em um momento posterior à aproximação. Na verdade, sob a perspectiva fenomenológica, uma idéia de abstrato humano normal ou patológico, isto é, um enunciado deste ou daquele tipo, seria considerado como resultado de um a priori não interessante à fenomenologia. Essa noção sobrepõe-se à idéia de epoché ${ }^{3}$ (e mesmo de outros conceitos fenomenológicos), que intentam "nada mais" do que uma aproximação de um objeto enquanto fenômeno.

A possibilidade de inserção do método e das principais idéias fenomenológicas nas ciências do homem, e mais especificamente na tentativa de captação e conseqüente compreensão do abstrato humano parece ser válida. Uma atitude filosófica transcendental que se direcionasse ingenuamente à subjetividade privatizada a ser compreendida enquanto fenômeno, a fim de revelar sua essência, é uma atitude fundamentalmente fenomenológica possível de ser realizada na ciência psicológica.

Os problemas até aqui abordados, embora refletidos, obviamente não estão solucionados. "Aliás, foram esses problemas que, no espaço de meio século, tornaram a clínica suspeita, provavelmente em justa razão, de participar da alienação justamente daqueles cujos distúrbios ela pretendia descrever exaustivamente, analisar objetivamente e classificar racionalmente" (Bercherie, 1989, p.21).

A construção dessa solução dar-se-á na própria evolução da Psicologia enquanto ciência, e enquanto prática clínica por aquela legitimada. Mesmo assim, a idéia do objeto científico psicológico enquanto subjetividade privatizada e a possibilidade (ainda que com sua suficiência questionada) de apropriação deste objeto através de uma postura intencional, talvez sejam o bastante para que então sejam discutidos alguns aspectos referentes às nuanças possíveis deste fenômeno privatizado, à luz da prática psicológica.

\section{As distinções (in) suficientes}

Discutir as nuanças dos fenômenos humanos privatizados é investigar as variações possíveis de apresentação do abstrato dos sujeitos. Na clínica psicológica, isso significa dizer que a idéia aqui é saber que tipo de variações mereceria uma intervenção. No entanto, a própria dificuldade da apropriação poderia interferir na identificação de uma variação ali presente. Essa dificuldade na apropriação pode

\footnotetext{
${ }^{3}$ Nesse sentido, o conceito de epoché pode ser compreendido como uma suspensão necessária de juízos não provenientes do próprio objeto, isto é, na atitude de intentar compreender um fenômeno, faz-se necessário abstrair-se, deixar um espaço vazio (na consciência) para que o objeto (sua essência) o preencha.
} 
ser um aspecto indispensável a ser considerado na complexidade da distinção entre o fenômeno humano normal e o fenômeno humano patológico que, em última instância, é o objeto central da clínica psicológica.

Historicamente, as concepções da enfermidade mental procuraram uma explicação (ou uma descrição apenas) dessa enfermidade, tomando como referência os aspectos observáveis relacionados à doença. Os indivíduos considerados enfermos poderiam assim ser classificados porque, visivelmente, possuíam um aspecto estranho, caminhavam com uma marcha diferente das outras pessoas, apresentavam maneiras distintas daquelas esperadas em vários contextos sociais, entre outras características consideradas, portanto, enfermas. Conseqüentemente, tais indivíduos não poderiam ter um lugar assegurado no seio de sua própria sociedade, por serem julgados incapazes de participar de forma suficiente desta composição social.

O indivíduo enfermo, se por um lado era considerado incapaz de assumir responsabilidades sociais em função de sua visível degradação, por outro lado, a falta dessa responsabilidade parecia justificar sua doença. Esse tipo de argumento relacionado à funcionalidade do indivíduo pode ser notado ainda hoje.

Na verdade, parece existir uma certa confusão acerca deste tema. Se parece ser justo o fato de que um acometimento de natureza física ou psicológica só possa ser considerado grave exatamente quando impede o indivíduo portador de "funcionar", a mesma justiça não seria tão evidente quando da consideração de uma enfermidade causada pela des-funcionalidade. Se existe uma diferença entre essas duas idéias - enfermidade enquanto causa de des-funcionalidade, e enfermidade enquanto conseqüência de des-funcionalidade, respectivamente -é porque a noção de funcionalidade não é independente; não pode ser tomada sem que seja contextualizada enquanto um juízo modelado pelas expectativas sociais de uma época e de uma geografia determinadas. O indivíduo funcional, portanto, é aquele indivíduo que funciona para algo ou para alguém, necessariamente.

Até aqui, a enfermidade mental é principalmente considerada enquanto uma entidade que subtrai de um determinado indivíduo, o enfermo, a possibilidade de que o desempenho social deste seja suficientemente razoável.

Parece haver, entretanto, outras possibilidades de entendimento de uma enfermidade mental. Sob outra perspectiva, que tivesse a preocupação de observar a doença de outras maneiras como, por exemplo, direcionando-se não mais à enfermidade em si, mas ao próprio indivíduo enfermo, a concepção acerca do fenômeno patológico humano teria a chance de ser modificada. Portanto, além da compreensão da doença mental não mais possuir os sintomas como ponto de partida, ela pode ainda aceitar a idéia de que seu objeto, a enfermidade, é extremamente diverso, porque assim o é a subjetividade privatizada, já que cada subjetividade corresponde a um, e somente um, sujeito em particular, em suas íntimas relações com seu contexto. De modo que, existindo diversas possibilidades de manifestação do abstrato humano, a enfermidade mental poder-se-ia ser entendida, finalmente, enquanto um fenômeno humano representativo dessa diversidade de subjetividades existentes, isto é, dos diferentes “modos-de-ser" deste abstrato humano (Holanda, 2001). 
A patologia mental, ainda, poderia também ser entendida como a síntese de um fenômeno humano não abarcado pela cultura imediata na qual o indivíduo observado está, inevitavelmente, inserido.

A partir do advento da Idade Moderna - normalmente compreendida do Renascimento - o homem explorou espaços até então desconhecidos, tendo tomado contato com outros sujeitos que não compartilhavam da cultura européia, construindo uma idéia de diferente que parece ter influenciado toda concepção clássica de enfermidade mental. Sendo estes "novos" povos então considerados selvagens, marcados por ausências: "sem moral, sem religião, sem lei, sem escrita, sem Estado, sem consciência, sem razão, sem objetivo, sem arte, sem passado, sem futuro" (Laplantine, 1999; Holanda, 2001); expandiu-se tal idéia mesmo àqueles europeus que compartilhavam da cultura européia, mas que "algo" lhe faltavam, ou que "algo" lhe sobravam, sendo que no primeiro caso o tratamento deveria repor, e no segundo, excluir (Todorov, s/d).

Mudando a direção do movimento de aproximação ao objeto a ser compreendido - agora já enquanto um fenômeno - o entendimento dessa subjetividade, aqui sendo representada pela patologia, partimos da apropriação daquela para só então inferir sobre esta última. Se a história médica repousa sobre a observação (descrição) dos sintomas para visualizar, e logo explicar a enfermidade ali subjacente, a perspectiva fenomenológica partirá da compreensão da própria subjetividade para entender que ali se manifesta um abstrato humano diferente, não necessariamente patológico e/ou des-funcional.

Sob uma ótica fenomenológica, essa doença é vista, ou apropriada, na modalidade de fenômeno, e não mais enquanto um conjunto de comportamentos observáveis do sujeito. Pode ser ainda que, segundo essa perspectiva, o espaço entre o fenômeno normal e o fenômeno patológico seja menos linear do que o espaço considerado nas concepções clássicas da crise do abstrato humano; de tal modo que as nuanças identificadas deste fenômeno apropriado, dentro desse espaço, possa estar em um locus não definido a priori pela própria idéia do binômio normalpatológico. A flexibilidade de poder transitar em algum grau neste espaço seria, portanto, característica desse fenômeno humano que, em última instância, é resultado de um movimento dialético composto por um apropriar-se e por um mostrar-se.

Compreender um abstrato humano apropriado enquanto fenômeno considerando que este processo seja possível a partir de uma nova metodologia , e a seguir identificá-lo em um lugar específico dentro de um espaço que contém a possibilidade da intervenção psicológica, é ainda um grande problema para a Psicologia em geral e para a Psicologia Clínica em particular. Assim, é também um problema a proposta de uma terapêutica para um fenômeno humano diferente, justamente pela dificuldade - talvez até mesmo pela impossibilidade - de se definir e localizar essa diferença satisfatoriamente em algum lugar.

Talvez por isto tenhamos um "lugar" tão vasto para as "terapêuticas" do

a humano; o que coloca a questão da Clínica como um ponto central relativo à discussão do espaço do humano na consideração da realidade. O espectro dessas "terapêuticas" 
abarca tanto as dimensões ditas subjetivas do humano (como o psicológico enquanto intrapsíquico, por exemplo), quanto às dimensões sociais e culturais, passando pelo biológico (com as neurociências, por exemplo), sem, contudo, deixar de lado a dimensão "transcendente" desse humano (como o espiritual, por exemplo, que acolhe essas demandas psicológicas num outro contexto) (Holanda, 2005).

\section{0 tratamento das (in) suficiências}

A proposta de um tratamento necessariamente tem sido justificada na possível constatação e localização de um “problema”, de um desvio suficiente em relação a alguma referência já estabelecida como norma. Sem dúvida, existe uma falta entre a apropriação e a terapêutica de um abstrato humano então considerado como desviante. Essa falta é caracterizada por um espaço no qual está inserida uma série de variáveis que suscitam questões em ambos os momentos (apropriação e terapêutica do abstrato humano).

Com relação ao primeiro momento, o essencial já está sendo aqui discutido (delimitação e método de alcance do abstrato humano enquanto fenômeno). Com relação ao segundo momento, constata-se, historicamente, que o tratamento dos abstratos humanos considerados desviantes está essencialmente ligado à retirada desses abstratos particulares do microcentro (este termo, no meu entendimento, refere-se ao espaço físico imediato das relações interpessoais imediatas; uma idéia que tenta sintetizar num mesmo termo os espaços físicos e subjetivos das relações humanas, significativas) da convivência social, fundamentada, conforme discutido anteriormente, na des-funcionalidade do sujeito considerado enfermo. O termo microcentro parece aqui ser pertinente no sentido de que, ao indivíduo excluído, também é reservado um papel social (o de ser o excluído), e mesmo um lugar na sociedade (na periferia). Assim, o excluído não é aquele que não pertence à sociedade, mas aquele que pertence ao lado de fora de sua própria sociedade.

Essa idéia foi confirmada na realidade através da constituição da instituição manicomial, que, nesse sentido, aproxima-se muito, enquanto finalidade última, de outras instituições totais (Goffman, 1974), sendo a penitenciária o protótipo desse tipo de lugar fatalmente destinado à exclusão social.

Segundo Goffman (1974), pode-se considerar cinco agrupamentos de instituições totais, estas sendo definidas como instituições que possuem "tendências ao fechamento (...), simbolizado pela barreira à relação social com o mundo externo e por proibições à saída que muitas vezes estão incluídas no esquema físico” (p.16). O primeiro destes agrupamentos é a penitenciária; o segundo agrupamento, no qual incluem-se os "locais estabelecidos para cuidar de pessoas consideradas incapazes de cuidar de si mesmas e que são também uma ameaça à comunidade, embora de maneira não-intencional” (pp. 16-17), contém o manicômio - ao lado dos "sanatórios para tuberculosos e leprosários" - que historicamente teria herdado exatamente o espaço físico dos leprosários extintos (Foucault, 1978). 
Acrescenta-se ainda que outro tipo de classificação às instituições totais poderia ser considerado: as que se concretizam como lugar da exclusão sem a consulta prévia ao indivíduo a ser retirado do convívio social imediato (como os manicômios e penitenciárias); e aquelas que permitem, em princípio, a escolha do indivíduo entre estar ou não na instituição (como os conventos e as escolas). A esta última categoria, acrescentaríamos um questionamento com respeito ao espaço da terapêutica clínica psicológica (em suas variadas formas): quanto esta formatação da clínica individual (e mesmo em alguns casos, da própria clínica grupal) estaria caminhando na mesma seara das instituições totais, que alienam o indivíduo de seu contexto de realidade, em nome de uma proposta de clínica subjetivada ${ }^{4}$. Entretanto, seria necessário um estudo mais detalhado para que tal idéia pudesse ser levada a cabo, particularmente porque, nessa proposta de classificação, o critério (escolha individual) é demasiado complexo.

Michel Foucault (1961) chegou mesmo a considerar a enfermidade como resultado também das contradições do meio no qual está o enfermo inserido. Tais contradições seriam de certa forma incorporadas pelo indivíduo, originando uma condição particular do abstrato deste. Assim, a enfermidade, mais do que o resultado de uma confusão ou des-regulação interna de um indivíduo teria sua gênese na incorporação dessas contradições sociais por parte deste indivíduo. Admitir, portanto, o sujeito enfermo dentro da sociedade imediata, seria admitir as confusões dessa própria sociedade.

É claro que aqui, poder-se-ia pensar então que toda pessoa que se apropria das contradições do meio vivenciaria uma patologia mental. Isso, todavia, não ocorre. A multicausalidade das patologias - especialmente aquelas de fundo psicológico - e a diversidade das subjetividades não suportam essa idéia. O processo de estabelecimento de uma enfermidade mental, assim, seria necessariamente caracterizado pelo resultado de uma configuração especial de uma série de fatores (orgânicos, genéticos, subjetivos e psicossociais em geral) localizada em uma história ontológica particular e única.

Por mais que a problemática da apropriação do abstrato humano não esteja superada, em especial quando se trata de uma apropriação alheia, esta apropriação, com uma metodologia mais específica, pode ser tentada. Então, a partir deste momento, existe uma nova possibilidade terapêutica. Que possibilidade seria essa?

Se os tratamentos do abstrato humano diferenciado, sempre ocorreram de formas muito questionáveis (no sentido terapêutico e especialmente no sentido ético), acontecendo sempre em um espaço asilar e, portanto, inadequado, isso é também reflexo de uma concepção e de uma apropriação insuficientes do fenômeno humano privatizado. O modelo asilar, nesse sentido, estaria expresso não apenas na modalidade física e geográfica (real), representada pelo manicômio, como também em uma modalidade imaginária, constituída de um saber prévio à compreensão

\footnotetext{
${ }^{4}$ Um bom exemplo disto pode ser encontrado em Coimbra (1992), onde a autora analisa as práticas clínicas no Brasil durante o regime da ditadura e constata a predominância dos modelos individualizados em detrimento dos modelos grupais, dado que melhor se adequavam às perspectivas políticas da época.
} 
desse fenômeno humano sempre diversificado e, de alguma forma, sempre novo, atualizado em cada sujeito.

Provavelmente, quando fundamentado em uma concepção e em uma compreensão do abstrato humano mais suficientes, o plano terapêutico poderia mudar de sentido, abrindo possibilidades outras de tratamento, enquanto formas e também enquanto espaços. Mudar a justificativa da terapêutica para o fenômeno humano patológico é essencial nesse sentido.

A idéia da des-funcionalidade de uma pessoa inserida em um contexto social deve ser substituída pela idéia da existência de um sofrimento experienciado pelo indivíduo. O tratamento não deveria ser justificado para simplesmente adaptar uma pessoa ao seu meio - carregado de papéis e regras bastante rígidos, que não permitem a des-adaptação de um indivíduo a estes, e que o isolam no caso dessa des-adaptação ocorrer. O tratamento deveria ser justificado, exclusivamente, em caso da constatação de um sofrimento pessoal devido à vivência de um processo preenchido por significados conflitantes construídos na interação entre esse indivíduo que sofre e seu meio, durante toda sua vida; interação esta particular de alguma forma, já que contribui em algum grau, como uma espécie de pano de fundo, à construção daqueles significados conflitantes no processo de subjetivação.

É importante ressaltar ainda que esse sofrimento necessariamente deveria ser legitimado pelo próprio sujeito, dono último de sua subjetividade, e não mais reconhecido apenas pelo profissional em contato com esta subjetividade alheia. Também não seria papel da cultura, sociedade, ou mesmo do meio social imediato no qual insere-se esta subjetividade, estabelecer (ou não) a presença de sofrimento psíquico no sujeito aí inserido. Pode ser que a justificativa única da terapêutica psicológica, pois, repouse em uma ética indispensável e particular.

De fato, obviamente, constatar um sofrimento pessoal alheio é também uma apropriação de uma subjetividade privatizada, que nesse caso, apresentar-seia em crise.

Alguns pontos podem ser retomados nesse momento para então serem relacionados à questão da terapêutica.

Pensando na complexidade da apropriação do abstrato humano enquanto fenômeno, o que parece ser essencial para sua compreensão, aliada à dificuldade de se interpretar ${ }^{5}$ tal fenômeno enquanto normal ou patológico, é possível questionar a idéia da terapêutica para este fenômeno, no sentido de sua necessidade (para quê tratar?) e de sua forma (como tratar?).

Este tratamento para o aspecto manifesto de um abstrato humano diferenciado pressupôs a idéia de comportamentos desviantes - em relação a uma

\footnotetext{
${ }^{5}$ Sob uma perspectiva fenomenológica, não faz sentido uma idéia de interpretação destacada de sua contextualização, ou seja, de uma hermenêutica. A noção de apropriação, sendo, a seu modo, uma redução fenomenológica, pressupõe também a compreensão de um dado fenômeno. Aqui, a idéia de interpretar está naturalmente contida na idéia de compreensão. A utilização da idéia de interpretação no texto é justificada para enfatizar o conhecimento qualitativo, e não apenas quantitativo, do fenômeno apropriado. Sobre esta questão, remetemos o leitor às considerações de Dilthey.
} 
média referente definida por um critério sempre parcial - para definir e localizar este abstrato então patológico; sendo essa terapêutica marcada historicamente enquanto mecanismo de retirada daquele elemento que se apresenta desadaptado de um contexto que não admite desadaptações, um contexto que não sabe lidar com o elemento diferente, um contexto que é ameaçado e que desorganiza-se na presença desse elemento. Nesse sentido, a histórica libertação dos doentes mentais, atribuída a Pinel ${ }^{6}$ "deve ser vista mais como uma reforma social do que como uma inovação no tratamento médico” (Szasz, 1979, p.34).

A terapêutica clássica, portanto, parece estar em sintonia com uma apropriação superficial da subjetividade humana privatizada que, não sendo capaz de compreender essa subjetividade enquanto fenômeno comprometeria - ou mesmo poderia impossibilitar - uma terapêutica verdadeira. Não sabendo cuidar daquilo que não se entendia, restava somente à instituição asilar enquanto possibilidade de manejo desse incômodo. E isso funcionou.

A história da terapêutica do fenômeno humano assistiu a uma prática caracterizada pelo tratamento pontual do que se pensava ser o problema (a ser tratado). Dessa forma, repousada na idéia de iatriké ${ }^{7}$, o que classicamente foi objeto de intervenção foi o aspecto manifesto, externo, daquela experiência de sofrimento. $\mathrm{O}$ foco do tratamento se voltou para o corpo ou, ainda menos, o papel social desse corpo.

Se se objetiva, entretanto, já não mais um tratamento, mas um cuidado dessa subjetividade humana em crise, é preciso que essa terapêutica seja mais ampla, alcançando aspectos outros do sujeito em terapia.

A idéia de therapeía, em contraste com a aquela idéia de "iátrico" (iatriké), intenta não o tratamento de um problema, mas o cuidado global do sujeito experiencial de sofrimento, o cuidado do ser desse sujeito (Ouaknin, 1996; Fílon de Alexandria, 1996; Leloup, 1996; Holanda, 2002), e isso não pode ser pensado fora da compreensão essencial desse sujeito, isto é, de seu processo de subjetivação, continente clínico do seu ser. Uma discussão nesse sentido parece ser indispensável ao campo da psicologia clínica, a ser realizada à luz da Psicologia, já que é esta que deve conter os fundamentos daquela.

\section{O cuidar do Psi}

Ao assumir a dificuldade de apropriação da subjetividade privatizada enquanto fenômeno; assumindo ainda a dificuldade de localização das nuanças

\footnotetext{
${ }^{6}$ Refere-se aqui às medidas tomadas entre 1780 e 1793 (no contexto da Revolução Francesa), que declaravam a desaparição do internamento nos hospitais franceses (Foucault, 1978). Liga-se esse fato ao médico francês Philipe Pinel, que procurou entender a enfermidade mental de outra forma, menos moral e mais orgânica, precursora da psiquiatria clássica. Agora, já não mais nos hospital gerais ou em outros locais de reclusão, os enfermos seria cuidados em casas especializadas em atenção mental.

- ${ }^{7}$ A idéia de iatriké e a idéia de therapeía são originárias do pensamento de Fílon de Alexandria. Fílon distingue a iatriké "medicina”, cuidar do corpo, da therapeía “terapia”, cuidar do ser (Ouaknin, 1996; Fílon de Alexandria, 1996).
} 
desse fenômeno entre as polaridades normal-patológico, uma outra possibilidade terapêutica emergiria somente sob um novo paradigma.

Anteriormente foi dito que a apropriação do fenômeno humano é construída dialeticamente entre objeto (fenômeno) e consciência intencional. Nesse sentido, é necessário um encontro especial entre esses dois elementos; um encontro que possibilite o desenvolvimento de um espaço único no qual poderá emergir a compreensão do fenômeno intencionado.

Passando da explicação à compreensão dessa subjetividade, a idéia de uma localização precisa, não-flexível, deste fenômeno em um momento na polaridade normal-patológico já não é essencial. Se, no caso de um fenômeno mostrar-se com características muito particulares - já não mais por serem diferenças suficientes em relação a uma normalidade pré-estabelecida, e sim porque tais características implicam sofrimento para a pessoa que experiencia tal fenômeno -, existe um lugar a ser preenchido por uma terapêutica.

Constatando-se, nesses moldes, a crise de uma subjetividade alheia, através da legitimação do próprio sujeito, existe a possibilidade do cuidado, e não mais simplesmente a possibilidade do tratamento. Muito mais do que o isolamento do elemento des-adaptado seja para simplesmente isolá-lo, seja para isolá-lo intentando uma reversão dessa des-adaptação, a terapêutica do psicológico precisa cuidar da experiência do sujeito que comporta o fenômeno particular; fenômeno este que, embora esteja localizado no indivíduo, reflete e é ainda constituído por elementos do meio ${ }^{8}$.

O cuidar é uma atividade. Frente a uma subjetividade em crise, isto é, ao deparar-se com uma pessoa em sofrimento psíquico real, o cuidado pode nascer efetivamente. E é só a partir desse momento que começa a tornar-se uma possibilidade real; o cuidado pode, finalmente, torna-se real de fato, no momento no qual emerge um "fazer alguma coisa", a partir da compreensão do sofrimento do outro. Essa idéia parece não ter estado sempre presente na história da terapêutica das enfermidades mentais. Na ausência de uma apropriação verdadeira do fenômeno humano diferenciado, em sofrimento, seja a estratégia de isolar pessoas em crise do meio social em um local bastante inapropriado, seja qualquer outra estratégia clínica que não tenha o pressuposto de compreender de fato seu objeto de investida, não parecem, ambas, serem a manifestação prática da therapeía.

Com relação à estratégia asilar, embora se tenha, aparentemente, resolvido alguns problemas de convívio, não se cuidou de fato daquele fenômeno

\footnotetext{
${ }^{8}$ O termo Dasein (ser-no-mundo) sintetiza a idéia de que a construção da subjetividade humana ocorre no espaço intersubjetivo, isto é, nas interações entre sujeito e mundo, no esteio da noção de Lebenswelt husserliana (Husserl, 1989). Neste sentido, é particularmente importante percebermos a potencialidade da proposta fenomenológica, como assinalado por Merleau-Ponty (1945, p.I): “Mas todo Sein und Zeit saiu de uma indicação de Husserl e nada mais é do que uma explicitação do "Naturlichen Weltbegriff" ou do "Lebenswelt" que Husserl, no fim de sua vida, dava como tema principal da fenomenologia...".
} 
diferenciado; e no caso de uma terapia desprovida de uma compreensão do fenômeno a ser investido, ainda que não se possa a priori constatar qualquer espécie de falha no cuidado, é possível inferir o risco iatrogênico de uma tal prática terapêutica, isto é, uma ação despreocupada com a essência da subjetividade ali manifesta no encontro clínico.

A proposta de tratar a própria sociedade, retirando de seu interior as pessoas que, por algum motivo, encarnaram as contradições deste meio social complexo, pode não estar totalmente superada. A subjetividade que sofre, não compreendida, é esquecida, mesmo que não seja geograficamente excluída. A ética das ciências humanas, em especial da Psicologia, muito mais do que uma questão de sigilo profissional, deveria fundamentar-se na responsabilidade profissional desse segundo momento, desse "e agora?", gerado a partir do contato com o sofrimento do outro, da subjetividade em crise apropriada pela "intencionalidade profissional".

O cuidado real acontecendo, portanto, na atividade de "fazer alguma coisa" com aquela subjetividade alheia em sofrimento real, não parece, em princípio, necessitar de um espaço exclusivo e único para existir. Sem a idéia de isolamento desse fenômeno em crise de seu convívio social, não há porque cuidar de uma pessoa que experimenta um sofrimento exclusivamente em algum lugar afastado, no sentido real e imaginário do termo. O lugar daquele que vivencia algo construído socialmente, dentro de seu próprio meio, é no interior deste mesmo meio; deve-se recordar que a experiência do sofrimento psíquico é constituída por elementos que contêm significados que são construídos na interação dialética entre sujeito e meio. Sob esse ponto de vista, o lugar geográfico da terapêutica psicológica pode ser ampliado a uma variedade de outros contextos classicamente não utilizados - ou mesmo recusados - pela clínica psicológica clássica.

Além de ter historicamente ocorrido em espaços específicos, uma outra característica da terapêutica psicológica estabelecida é a proposta do tratamento remediativo. Somente a partir da consideração enquanto patologia de um determinado comportamento que é então proposto um agir sobre este, com o intuito de ou isolá-lo, ou de modificá-lo para não se ter de isolá-lo. A idéia de um cuidado posterior ao estabelecimento de uma condição particular não é totalmente negativa. Inclusive, uma outra forma de cuidado talvez não seja de fato possível já que, para o cuidar, é preciso apropriar-se da subjetividade do outro, e esta é uma condição que, temporalmente, ocorre anteriormente ao "fazer alguma coisa" com esta subjetividade. Entretanto, entendendo exatamente essa apropriação como um processo, dialético inclusive, construído em um lugar comum único que emerge no encontro entre duas subjetividades distintas (consciência intencional e fenômeno intencionado), uma leitura diferenciada dessa questão temporal poderia ser possível.

A apropriação da subjetividade privatizada - o abstrato humano do outro a - é, fundamentalmente, o ponto de partida da clínica psicológica aqui discutida, o primeiro momento. O segundo momento se caracterizaria pelo fato do terapeuta - 
localizado do lado da consciência intencional que, no ambiente terapêutico, é o mesmo lado que contém um saber e, logo, um poder inegável e irrecusável (Bucher, 1989) - iniciar uma intervenção profissional localizada nesse espaço comum, criada quando do encontro essencial entre intenção e fenômeno.

Assim, a clínica decorrente da apropriação e do agir sobre o fenômeno humano apropriado nos moldes aqui explicitados, talvez seja uma clínica diferente. Não parece, nesse sentido, existir um corte muito rígido entre os dois distintos momentos explicitados acima, quando do encontro terapêutico: o apropriar-se e o cuidar subseqüente. Na verdade, esse corte não seria nada rígido, talvez mesmo inexistente. Poder-se-ia compreender o lugar dessa clínica no momento em que a idéia de apropriação do fenômeno começa a dar lugar, necessariamente, à idéia de cuidado desse fenômeno, sem que a primeira se torne ausente na presença da segunda. Inclusive, no contexto clínico, a segunda idéia (cuidado) já ronda o primeiro momento (apropriação) no encontro das duas subjetividades.

Assim, a temporalidade dessa clínica nova não se divide em dois distintos momentos; ela corre horizontalmente, sem pressa, sem estabelecer uma hierarquia de tarefas a serem cumpridas em uma ordem pré-estabelecida. O importante é que o encontro entre duas subjetividades aconteça de fato; o essencial é o estar junto.

Quando uma subjetividade, representada por uma consciência intencional, encontra uma outra subjetividade, representada por um abstrato humano particular - na modalidade de fenômeno, quando apropriado - que experiencia sofrimento psíquico, e, na mesma temporalidade, emerge (já presente na apropriação) a possibilidade do cuidado desse fenômeno, então existe a clínica.

São as condições de existência aqui descritas dessa clínica que, muito mais do que condições são aspectos presentes no encontro, abrem a possibilidade temporal e espacial dessa clínica nova. É possível que este encontro que torna a clínica possível (encontro que contém uma apropriação e cuidados verdadeiros), possa acontecer em muitos contextos.

Não existiriam, portanto, um tempo e um lugar físico (ou mesmo imaginário), específicos para essa clínica; existiriam sim apenas as condições (aspectos que emergem do encontro), já aqui enunciados.

Nesse sentido, existiria, no interior dessa clínica, um lugar para o aconselhamento psicológico, entendido como um espaço clínico caracterizado por um tempo cronologicamente limitado, capaz de propiciar esse tipo de encontro, no qual a relação entre o sujeito dono de sua subjetividade em crise e o terapeuta, coexistindo, buscariam, dentro do lugar comum criado por esse encontro, o clareamento dos significados vivenciais e relacionais experienciados por aquela subjetividade (Spanoudis, 1997).

Na prática do aconselhamento ainda é possível situar a importância da idéia de encaminhamento. Devido ao tempo cronológico reduzido da clínica do aconselhamento, e mesmo devido a uma das possíveis justificativas desse 
tipo de clínica ${ }^{9}$, a possibilidade do encaminhamento - seja à psicoterapia breve, às psicoterapias clássicas, ou a qualquer outro serviço psicológico ou mesmo outros serviços de saúde, além de várias possibilidades de encaminhamento a serviços em geral de atenção à pessoa - está sempre disponível. Assim, o aconselhamento psicológico, de certa forma, é uma clínica que contém também um sentido preventivo; acrescenta-se ainda que o cuidado proveniente da idéia de therapeía parece suportar a noção de um cuidado preventivo. Esse motivo, além daquele da possibilidade do encontro clínico não necessitar de um espaço específico, favorece a ampliação dos contextos possíveis para a clínica nova psicológica, sendo o aconselhamento uma de suas várias possibilidades.

Retornando à questão do encontro clínico, alguns conceitos derivados da Abordagem Centrada na Pessoa, construída por Carl Rogers (1992, 2002), refletem sua possibilidade: consideração positiva e incondicional, congruência e compreensão empática por parte do terapeuta, idéias constituintes das três condições necessárias (e suficientes). A Psicanálise, de alguma forma, também procurou aproximar-se o máximo do abstrato humano em crise; pode-se notá-lo na tópica que suporta a idéia de inconsciente e em todas as tentativas de alcançálo (hipnose e sugestão, sonhos, associação livre). A idéia de um escuta clínica é ainda um conceito fundamental nesse sentido: cabe ao terapeuta "ver" aquilo que o sujeito lhe diz, de forma que aquele possa ir entrando em contato com a subjetividade deste, de modo mais essencial possível, para que então possa compreendê-la.

De qualquer maneira, não é conveniente pousar neste momento, e nesse espaço, uma discussão dessa natureza. Aliás, qualquer construção teórico-prática neste campo, precisa ser sincera e assumir suas limitações, inclusive o saber fenomenológico. Como constatou Bercherie (1989):

A verdade é que, na exploração sistemática do acesso ao real que é aberto por uma dada orientação, passada uma fase de extensão em todas as direções, na qual se efetua a primeira coleta de "fatos" concretos e se fazem as primeiras generalizações sistematizadas, acaba por se acumular toda uma massa de observações fortuitas, de exceções à regra, de fatos difíceis de se enquadrarem nas doutrinas oriundas da fase de expansão (...). (p. 25)

\footnotetext{
${ }^{9}$ A clínica do aconselhamento psicológico reconhece seu lugar e seu papel na clínica psicológica em geral, diferenciando-se das outras práticas (psicoterapia, psicoterapia breve) inclusive em relação aos seus objetivos. Não é função do aconselhamento promover uma mudança qualitativa da personalidade do indivíduo atendido, como parece propor a clínica psicoterápica. Uma das justificativas do aconselhamento psicológico é a possibilidade de ser um espaço para o primeiro contato de uma pessoa com um serviço psicológico, oferecendo um suporte psicológico imediato, uma orientação psicoeducativa caso haja uma demanda focal do indivíduo em atendimento e, finalmente, possíveis opções de continuidade de uma atenção psicológica mais aprofundada, inclusive psicoterapia.
} 
O exercício, isto é, a responsabilidade de construir concepções, métodos e práticas mais suficientes relacionados à subjetividade privatizada em crise não é de um ou outro saber de natureza ou intenção psicológica; essa responsabilidade é absolutamente necessária a todos os saberes que intencionam o abstrato humano. Trata-se de uma busca; talvez uma busca interminável e, por isso mesmo, indispensável.

\section{À Guisa de Conclusão}

É possível que a reflexão a respeito das bases epistemológicas da Psicologia e da clínica psicológica forneça subsídios para uma nova prática. Entender a dificuldade da Psicologia de estabelecer-se enquanto ciência é o ponto de partida. A dificuldade de delimitação de um objeto científico ainda não está totalmente solucionada, embora se tenha avançado bastante na identificação desse objeto, entendido aqui como a subjetividade privatizada.

Outro problema, este aparentemente ainda mais distante de uma solução, é o da dificuldade no alcance deste objeto, atitude indispensável para a compreensão do mesmo. Compreender o abstrato humano, compreender a experiência sofrível eventual desse abstrato, superpor um cuidado a essa experiência são atividades que demandam novas concepções desse abstrato humano tão abstrato. É necessário continuar na direção da compreensão essencial do abstrato humano. Nesse sentido, o método fenomenológico, caracterizado pela intencionalidade à apropriação, enquanto fenômeno, da subjetividade privatizada, foi aqui proposto, mesmo levando em consideração que "a complexidade da fenomenologia permite adaptações muito pessoais” (Beauchesne, 1989, p.131).

A localização de um lugar dentro de uma polaridade normal-patológico para esse fenômeno, parece estar diretamente relacionada com as propostas terapêuticas clássicas até então levadas a cabo. Assim, ocorreu que, quando comparado a um comportamento padrão desejado, ou seja, a uma referência determinada, o abstrato humano que incomodava o meio social foi isolado desse convívio. Não parece, dessa forma, que a terapêutica focava o indivíduo, mas sim a própria sociedade, retirando desta aquilo que a incomodava. Um tratamento dessa natureza reflete a compreensão ainda insuficiente dos fenômenos humanos, da subjetividade privatizada do outro. Apropriar-se de fato dessa subjetividade, isto é, compreendê-la enquanto fenômeno parece ser um indispensável primeiro passo em direção a uma (nova) clínica nova. A seguir, portanto, o segundo passo seria considerar que uma intervenção neste fenômeno só se justificaria em caso de o sujeito, o qual vivencia tal fenômeno, experienciasse um sofrimento psíquico por ele autenticado (e não apenas uma des-funcionalidade ou um exotismo).

Essas condições justificantes poderiam existir somente em um lugar comum; um espaço a ser preenchido entre duas diferentes subjetividades - portanto, uma inter-subjetividade - que experienciariam um encontro de fato, possibilitando a 
manifestação, nesse lugar, do ser do sujeito a ser cuidado (de acordo com o sentido da idéia de therapeía).

Uma tal clínica não demandaria nem um espaço nem um tempo específicos para existir, nem mesmo pré-supostos definidos. Em um único encontro clínico, por exemplo, poder-se-ia constatar ali um verdadeiro encontro entre dois abstratos humanos constituídos de uma compreensão de uma subjetividade em sofrimento autêntico seguida, necessariamente, de um cuidado, concretizado, na clínica psicológica, por um alívio daquele sofrimento ${ }^{10}$.

Ampliam-se, assim, as possibilidades da clínica psicológica para muitos outros contextos (espaciais e temporais), além daqueles nos quais, tradicional e classicamente, tal prática já acontece.

\footnotetext{
${ }^{10}$ Não é possível definir, a priori, o significado prático de alívio psíquico ou psicológico. Ainda, não parece haver um consenso, dentre as várias correntes psicoterápicas, no que tange ao resultado esperado de um processo psicoterápico. Tal problema pode ser ainda mais complexo no campo da clínica psicológica de curta duração, isto é, do aconselhamento psicológico e das psicoterapias breves, justamente pelo fato de o possível resultado terapêutico ser, em princípio, menos observável, pelo terapeuta e pelo sujeito em atendimento, em um ou poucos encontros. De qualquer forma, este termo (alívio) é aqui utilizado exatamente para diferenciar os objetivos clínicos das psicoterapias, das psicoterapias breves, e do aconselhamento psicológico. Este último tipo de clínica psicológica, claramente, possui um objetivo mais focal e imediato de atuação, com a expectativa, portanto, de uma melhora clínica também mais imediata e focal, diferentemente dos outros tipos de clínica psicológica, em especial às psicoterapias, que, de modo geral, buscam principalmente promover o crescimento e o desenvolvimento da personalidade (Wolberg, 1988) do indivíduo atendido. Enfatizase aqui, finalmente, que a melhora clínica parece depender muito mais de fatores relacionados à compreensão do sofrimento alheio e à ética do cuidado, e menos de um tempo e de um lugar específicos.
} 


\section{Referências Bibliográficas}

Beauchesne, H. (1989). História da psicopatologia. São Paulo: Martins Fontes.

Bercherie, P. (1989). Os fundamentos da clínica: história e estrutura do saber psiquiátrico. Rio de Janeiro: Jorge Zahar.

Bornheim, G. A. (Org.) (1993). Os filósofos pré-socráticos. $9^{\mathrm{a}}$ ed. São Paulo: Cultrix.

Bucher, R. (1989). A Psicoterapia pela Fala: fundamentos, princípios, questionamentos. São Paulo: E.P.U.

Buzzi, A. R. (1989). Introdução ao pensar: o ser, o conhecimento, a linguagem. $18^{\mathrm{a}}$ ed. Petrópolis: Vozes.

Coimbra, C.M.B. (1992). Gerentes da Ordem: algumas práticas "psi” nos anos 70 no Brasil, Tese de Doutorado em Psicologia, São Paulo: Universidade de São Paulo.

Faria, N. J. \& Brandão, S. C. (2004). Psicologia Social: indivíduo e cultura. Campinas: Editora Alínea.

Figueiredo, L. C. M. \& Santi, P. R. L. (2003). Psicologia: uma (nova) introdução. $2^{\mathrm{a}}$ ed. São Paulo: EDUC.

Fílon de Alexandria (1996). De Vita contemplativa, Em Jean-Yves Leloup, Cuidar do Ser. Fílon e os Terapeutas de Alexandria. Petrópolis: Vozes.

Foucault, M. (1961). Enfermedad mental y personalidad. Buenos Aires: Editorial Paidos.

Foucault, M. (1978). História da loucura na Idade Clássica. São Paulo: Perspectiva.

Foucault, M. (1984). Doença Mental e Psicologia. Rio de Janeiro: Tempo Brasileiro.

Foucault, M. (1987). O Nascimento da Clínica. Rio de Janeiro: Forense-Universitária.

Goffman (1974). Manicômios, prisões e conventos. São Paulo: Perspectiva.

Holanda, A. B. (1986). Dicionário da língua portuguesa. $2^{\mathrm{a}}$ ed. Rio de Janeiro: Nova Fronteira.

Holanda, A. F. (2001). Psicopatologia, exotismo e diversidade: ensaio de antropologia da psicopatologia, Psicologia em Estudo, Maringá, Vol.6, Nr.2, p.29-38. Disponível na World Wide Web:

http://www.scielo.br/scielo.php?script=sci_arttext\&pid $=$ S141373722001000200005\&lng $=$ pt\&nrm $=$ iso 
O Aconselhamento Psicológico e as Possibilidades de uma (Nova) Clínica Psicológica

Holanda, A.F. (2002). O Resgate do Pensamento de Husserl e a Pesquisa em Psicologia, Tese de Doutorado em Psicologia. Campinas, Pontifícia Universidade Católica de Campinas.

Holanda, A.F. (2005). Mysterium Tremendum - Psicologia da Religião e a Questão da Psicopatologia, Anais do XI Encontro Goiano da Abordagem Gestáltica (Goiânia/GO), p.53-67.

Husserl, E. (1965). A Filosofia como Ciência de Rigor. Coimbra: Atlântida.

Husserl, E. (1980). Méditations Cartésiennes. Introduction à la phenomenology. Paris: Librairie Philosophique J.Vrin.

Husserl, E. (1985). Idées Directrices pour une Phénoménologie et une Philosophie Phénoménologique Pures. Paris: Gallimard.

Husserl, E. (1989). La Crise des Sciences Européennes et la Phénoménologie Transcendantale. Paris: Gallimard.

Husserl, E. (1992). Conferências de Paris. Lisboa: Edições 70.

Jaspers, K. (1987). Psicopatologia Geral. São Paulo: Livraria Atheneu.

Kolakowski, L. (1983). Husserl y la Búsqueda de la Certeza. Madrid: Alianza Editorial.

Laplantine, F. (1999). Aprender Antropologia. Editora Brasiliense.

Leloup, J-Y. (1996). Cuidar do Ser. Fílon e os Terapeutas de Alexandria. Petrópolis: Vozes.

Lyotard, J. F. (1954). A Fenomenologia. Lisboa: Edições 70. Coleção Básica de Filosofia.

Merleau-Ponty, M. (1945). Phénoménologie de la Perception. Paris: Gallimard.

Ouaknin, M-A. (1996). Biblioterapia. São Paulo: Edições Loyola.

Piaget, J. (2002). Epistemologia genética. $2^{\mathrm{a}}$ ed. São Paulo: Martins Fontes.

Rogers, C.R. (1992). Terapia Centrada no Cliente. São Paulo: Martins Fontes.

Rogers, C.R. (2002). Tornar-se Pessoa. São Paulo: Martins Fontes.

Spanoudis, S. (1997). A tarefa do aconselhamento e orientação a partir da Daseinanalyse. Daseinanalyse, 1, 2 e 4, pp. 56-62.

Szasz, T. S. (1979). O mito da doença mental. Rio de Janeiro: Jorge Zahar. 
Todorov, T. (s/d). Nous et les Autres: La réflexion française sur la diversité humaine. Paris: Éditions du Seuil.

Vygotsky, L. S. (2002). A formação social da mente. $6^{\mathrm{a}}$ ed. $5^{\mathrm{a}}$ tiragem. São Paulo: Martins Fontes.

\title{
Wolberg, L.R. (1988). The Technique of Psychotherapy. Philadelphia: Grune \& Stratton.
}

\begin{abstract}
Starting from the reflection on the epistemological basis epistemológicas of Psychology, this work has as objective verifies some fundamental subjects to the psychological clinic. Some main difficulties in relation to the scientific object of the psychological science are approached. Some are proposed foundations on phenomenology that could be useful in the appropriation attempt and understanding of this psychological object. It can be possible to base a clinical practice constituted by a deeper understanding of the human phenomena that are experienced with suffering by the subject in focus, following by a subsequent and inevitable care. Such elements seem to exist only in a common place produced in the encounter among two different subjectivities. In that way, the psychological clinic can happen in a variety of contexts, besides those us which she already happens. The psychological counseling, understood here as a possibility of occurrence of that fundamental clinical encounter, even if in a reduced temporary gradient, then he/she can have a room in the spectrum of the classic psychological clinic.
\end{abstract}

Keywords: Psychological Counseling; Phenomenology; Clinical psychology; Epistemology.

Resumen: A partir de reflexiones acerca de las bases epistemológicas de la Psicología, este trabajo tiene como objectivo verificar cuestiones fondamentales a la clinica psicológica. Algunas dificultades en relación a lo objecto científico de la ciência psicológica son abordados, haciendo la proposición de los fundamientos fenomenológicos como utiles para la comprensión de este objecto psicológico. Es posible fundamentar uma practica clinica construída cerca de una compreensión más aprofundada de los fenómenos humanos que son experienciados com sofrimiento por la persona, seguido de lo cuidar. Estes elementos parecen existir solamente en un lugar comum producido em el encuentro entre duas subjectividades distintas. La clinica psicológica puede ocurrir en uma variedad de contextos. El aconsejamiento psicológico, comprendido como la posibilidad de lo encuentro clínico fundamental, puede entonces tener un lugar en el espectro de la clinica psicológica clasica.

Palabras-Clave: Aconsejamiento Psicológico; Fenomenología, Psicología Clinica, Epistemología.

Fernando de Barros é psicólogo, graduado pela Universidade de Brasília (UnB). Email: fernandoramone@yahoo.com

Adriano Holanda é psicólogo, Doutor em Psicologia, Professor do Curso de Psicologia do Iesb (DF) e Coordenador do Curso de Psicologia da Faculdade Alvorada (DF). Email: aholanda@yahoo.com

Recebido em 10.02.07

Primeira Decisão Editorial em 26.03.07

Versão Final em 15.04.07

Aceito em 23.04.07 